\title{
Characterization of ethylene-vinyl acetate (EVA)/modified starch expanded compounds for outsole material
}

\author{
Dwi Wahini Nurhajati*, Umi Reza Lestari, Gunawan Priambodo \\ Center for Leather, Rubber and Plastics, Ministry of Industry, Jl. Sokonandi No. 9 Yogyakarta 55166, Indonesia \\ * Corresponding author. Tel.: +62 274 512929; Fax: +62 274563655 \\ E-mail: dwiwahini@gmail.com
}

Submitted: 24 March 2021

Revised: 12 April 2021

Accepted: 17 May 2021

\begin{abstract}
The use of non-biodegradable material in shoe components has negative impacts on environmental sustainability when disposed into landfills due to poor biodegradability. This study prepared ethylene-vinyl acetate (EVA)/ modified starch expanded compounds as outsole material to overcome environmental pollution. This research aimed to investigate the effects of EVA/modified starch ratio on the properties of the compound. Ethylene-vinyl acetate (EVA) copolymer was blended with a modified cassava starch in various amounts (10-50 phr) using a two-roll mill. Effect of modified starch content was characterized its tensile strength, elongation at break, tearing strength, $50 \%$ permanent set, density, abrasion resistance, flex resistance, biodegradability, and morphology. The optimum value of tensile strength $\left(61.33 \mathrm{~kg} / \mathrm{cm}^{2}\right)$, elongation at break $(895 \%)$, and tear strength $(16.62 \mathrm{~N} / \mathrm{mm})$ were obtained for samples containing $20 \mathrm{phr}$ modified starch. The EVA compound containing $30 \mathrm{phr}$ of starch showed the optimum $50 \%$ permanent set $(4.85 \%)$ and the highest abrasion resistance with the smallest volume loss of $439.99 \mathrm{~mm}^{3}$. The addition of modified starch up to $50 \mathrm{phr}$ provided good flexural resistance to 150000 number of cycles. The morphology image showed that distribution of modified starch particles was not homogeneously dispersed in the EVA/modified starch expanded compound. Incorporation of modified starch in EVA compound was improving its biodegradability.
\end{abstract}

Keywords: biodegradability, EVA, modified starch, morphology, outsole, physical properties.

\section{INTRODUCTION}

The use of non-biodegradable material in shoe components has negative impacts on environmental sustainability when disposed into landfills because of its poor biodegradability. Therefore, the researchers strive to produce shoe components materials that environmental friendly. The outsole is one of the important shoe components that directly contact with the ground. In the footwear industry, ethylene-vinyl acetate copolymer (EVA) is widely used in the manufacture of shoe components including outsoles and insoles (Lopes et al., 2015), which brings several benefits such as cost reduction, comfort, lightness, and softness (Ferreira, 2018).

Ethylene Vinyl Acetate (EVA) is a copolymer consisting of ethylene and vinyl acetate (Sisanth, 2017, Brito e Dias et al., 2018). The end property depends on vinyl acetate (VA) content; VA content usually varies from 10 to $40 \%$ (Nautiyal, 2012), the elastomeric grade of EVA consists of VA content varying from $40-60 \mathrm{wt} \%$ (Sisanth, 2017). The application of EVA for footwear has been reported by many researchers. Liu (2017) reported the application of EVA as the support layer shock absorption material for basketball shoes. A study related to EVA as a material for shoe midsoles has been reported by Wang (2012) and Onodera (2017). Lopes et al. (2015) reported natural and synthetic rubber/waste-EVA (Ethylene-vinyl acetate) composites for sustainable application in the footwear industry. The production of many petroleum-based products, such as EVA, used to manufacture footwear results in serious environmental pollution when disposed of into landfills because of its less biodegradability. To increase the biodegradability of EVA, natural polymers were added to make a mixture. Starch is popular for its ability to be fully biodegradable in land and water, as well as elevates the 
biodegradability of non-biodegradable plastics (Gautam \& Kaur, 2013; Tanase et al., 2016; Sessini et al., 2019).

The biodegradability of starch and its low cost are some points that make increasement of starch application in the polymer industry. It also fits in with the eco-friendly trends supported by law regulations. Starch can be modified into thermoplastic starch (TPS) to enhance its processing and potential applications. The most common plasticizers which added to make TPS are the mixture of water and glycerol (Obashi and Igwe, 2014; Maran et al., 2014; Mendes et al., 2016). According to Valle et al. (2018), TPS has been blended with many polymers such as polyvinyl alcohol (PVA), polylactic acid (PLA), Poly(E-caprolactone) (PCL), polyhydroxybutyrate (PHB), and other polymers. Blend of TPS with EVA in food packaging applications have been reported by Da Roz et al. (2012), Rodriguez-Perez et al. (2012), and Sessini et al. (2019). To our knowledge, the blends of EVA/TPS for outsole materials have not been reported by researchers.

In the footwear industry, EVA is one of the materials which popularly known as expanded rubber or foam rubber. It is necessary to make a mixture to obtain an expanded compound that will determine the required material characteristics so EVA can be molded on the outsole process. The expanded compound processing is usually associated with the incorporation of blowing agents during compound processing. Blowing agents commonly used for the formation of cellular structures in polymeric matrices can be physical, such as liquids with low boiling points, or solid chemical compounds that decompose under heat by releasing gases such as nitrogen and carbon dioxide (Zimmermann et al., 2014). Azodicarbonamide is the most popular blowing agent to produce EVA. The solid form of azodicarbonamide deteriorate into gas when its heated. The gas then extends to form tiny bubbles when its confined inside the semi-liquid plastic EVA compound. This study aimed to investigate the effects of EVA/modified starch ratio on the properties of EVA/modified starch expanded compound.

\section{MATERIALS AND METHODS Materials}

Rubber grade EVA (Levapren 500) with vinyl acetate (VAc) content of $50 \mathrm{wt} \%$ and Indonesia tapioca flour (trade name Orang Tani) with 17.87 wt $\%$ amyloses and $82.13 \mathrm{wt} \%$ amylopectin content were purchased from a local supplier. The commercial-grade of chemicals such as dicumyl peroxide (DCP) as a crosslinking initiator, glycerol, and water as a starch plasticizer, $\mathrm{CaCO} 3$ (filler), azodicarbonamide (ADCM) as a foaming agent, $\mathrm{ZnO}$ as an activator, stearic acid as a coactivator, $\mathrm{Zn}$ stearic as a lubricant were purchased from a local supplier. The compost and effective microorganism 4 (EM4) were purchased from a local supplier

\section{Methods \\ Preparation of modified starch}

Firstly, tapioca starch was modified by mixing the starch with water and glycerol at 60:25:15 of starch-glycerol-water ratio. These materials were mixed thoroughly by using a high-speed mixer at 350-500 rpm until attaining a homogeneous powder for $45 \mathrm{~min}$. The mixture then kept for 2 days in a plastic bucket to plasticize and swell the granular starch molecule.

\section{Preparation of EVA/modified starch expanded compound}

EVA/modified starch expanded compounds were prepared by mixing EVA, modified starch, and additives using a two-roll mill laboratory scale. The blends were prepared according to the formulation in Table 1. The ratios of EVA/ modified starch were varied from 100/0; 90/10; $80 / 20 ; 70 / 30 ; 60 / 40$ and 50/50. After completion of the mixing process, the compounds were allowed to rest $24 \mathrm{~h}$ at $25^{\circ} \mathrm{C}$ before subsequent processes. Subsequently, these EVA/modified starch expanded compounds were molded into a sheet using an electrically heated hydraulic press at $165{ }^{\circ} \mathrm{C}, 150 \mathrm{~kg} / \mathrm{cm}^{2}$ for 15 minutes (for $2+0.1$ $\mathrm{mm}$ thickness) and 20 minutes (for $6+0.1 \mathrm{~mm}$ thickness).

\section{Characterization}

Testing of tensile strength, elongation at break, and tear strength were performed on a Universal Testing Machine (UTM, Tinius OlsenH25K). Tensile strength and elongation at break test specimens were prepared according to ISO 37:2017(E) with a dumbbell-type 2 specimen. The tests were done at laboratory temperature $\left(23 \pm 2{ }^{\circ} \mathrm{C}\right)$ with a crosshead speed of $500 \mathrm{~mm} /$ min. The tear strength of samples was measured 
Table 1. The formulation of EVA/modified starch expanded compounds.

\begin{tabular}{ccccccccc}
\hline \multirow{2}{*}{$\begin{array}{c}\text { Sample } \\
\text { code }\end{array}$} & \multicolumn{8}{c}{${\text { Ingredients }(\mathrm{phr})^{\mathrm{a}}}^{\mathrm{n}}$} \\
\cline { 2 - 9 } & EVA, & Tapioca starch, & $\mathrm{CaCO} 3$ & ZnO & Zn stearate & Stearic acid & DCP & ADCM \\
\hline MS0 & 100 & 0 & 1 & 3 & 0,5 & 2 & 0,5 & 5 \\
MS10 & 90 & 10 & 1 & 3 & 0,5 & 2 & 0,5 & 5 \\
MS20 & 80 & 20 & 1 & 3 & 0,5 & 2 & 0,5 & 5 \\
MS30 & 70 & 30 & 1 & 3 & 0,5 & 2 & 0,5 & 5 \\
MS40 & 60 & 40 & 1 & 3 & 0,5 & 2 & 0,5 & 5 \\
MS50 & 50 & 50 & 1 & 3 & 0,5 & 2 & 0,5 & 5
\end{tabular}

aphr: parts per hundred parts of resins by weight

in accordance with ISO 34-1:2015(E) with an angle-type specimen using. The values presented were the mean values of three measurements in all cases.

Density was tested according to ISO 2781:2018(E) Method A by comparative measurement of samples mass in air and water using an Electron Densimeter (EW-200SG) from Mirage. Abrasion resistance test was done with a rotary drum abrasion tester (Bareiss) according to ISO 4649:2017 using the cylindrical shape specimens with a diameter of $16 \pm 0.2 \mathrm{~mm}$ and a height of $6 \mathrm{~mm}$. Abrasion resistance test result was expressed as a relative volume loss compared to an abrasive sheet calibrated using a standard reference compound.

The test of $50 \%$ permanent set (permanent extension) was characterized according to the relevant Indonesia National Standard test methods SNI 0778:2009 Sol Karet Cetak using a Permanent Set Tester. The flex resistance test was measured by using a Ross flexing machine and the flex continued up to $150 \mathrm{kcs}$ according to the relevant Indonesia National Standard test methods SNI 0778:2009 Sol Karet Cetak point 6.2.7. The morphology of the EVA/modified starch expanded compounds was characterized by a Video measuring system (ARCS-SI 901).

The biodegradation test was carried out by the burial method in the compost soil. Biodegradability of the EVA/modified starch expanded compounds was evaluated by weight loss percentage (WLP) according to ASTM D-5988. The blends were cut into dumbbell shapes (a dumbbell-type 2 specimen). These dumbell specimens were buried in a plastic pot containing compost enriched with effective microorganism 4 (EM4). The compost containing manure, charcoal husk, sand, soil, and cocopeat. The specimens were buried in the compost at a depth of $10 \mathrm{~cm}$ from the surface to be the subject of attacking microorganisms in compost. The tested period was 14 days and lasted 48 days. The formula of WLP was as follows,

$\operatorname{WLP}(\%)=\left[\left(\mathrm{W}_{0}-\mathrm{W}_{1}\right) / \mathrm{W}_{0}\right] \times 100 \%$

Where WLP (\%) refers to the weight loss percentage of the specimen; $\mathrm{W}_{1}$ refers to the weight of specimen after degradation; $\mathrm{W}_{0}$ refers to the weight of the specimen before degradation.

\section{RESULTS AND DISCUSSION Tensile Strength}

The tensile strength of a material is a parameter of how much stress in the form of tension a material can accept before it finally breaks. Tensile strength of the EVA/modified starch expanded compounds containing various modified starch content were shown in Figure 1.

The modified starch loading gave a different response to the tensile strength properties of the blends. The addition of modified starch up from 10 to $30 \mathrm{phr}$ increased the tensile strength as compared to the blends without modified starch (MS0). The tensile strength of the EVA compound without modified starch was $26.87 \mathrm{~kg} / \mathrm{cm}^{2}$ while with the addition of $10 \mathrm{phr}$ modified starch expanded to $39.2 \mathrm{~kg} / \mathrm{cm}^{2}$, which means that there was an increase of $45.89 \%$. The optimum tensile strength $\left(61.33 \mathrm{~kg} / \mathrm{cm}^{2}\right)$ was obtained at $20 \mathrm{phr}$ modified starch loading due to good dispersion of starch into the EVA matrix.

The good dispersion of starch into the EVA matrix was validated by morphology image (see Figure 8b). However, with a further increase in starch loading, the tensile strength gradually decreased. The decrease in tensile strength at the higher starch concentration (40-50 phr) was due 
to starch-starch interaction more dominance than the starch-EVA interaction, which resulted in agglomeration of the starch particles. It could be seen in the morphology images (Figure 8). The agglomerates arose due to the inhomogeneous distribution of the filler in the matrix, thereby reducing the interfacial tensile force and weakening the tensile strength (Fang et al., 2014). According to Ayu et al. (2018) and Hamadache et al. (2019) increasement of starch content produces more voids, resulting a weakening structure of the blends due to poor interfacial bonding between polymer matrix and starch.

The Indonesian National Standard (SNI) for the EVA/starch base expanded compound for outsole did not exist yet, and international standards have not been found either. For this reason, the quality of the resulting expanded compound was compared with the quality requirements of SNI 0778:2009 Sol Karet Cetak for quality classification 3 with a minimum tensile strength value of $50 \mathrm{~kg} / \mathrm{cm}^{2}$. The tensile strength values of the expanded compound containing 20 and $30 \mathrm{phr}$ of modified starch were $61.33 \mathrm{~kg} / \mathrm{cm}^{2}$ and $55.63 \mathrm{~kg} / \mathrm{cm}^{2}$ respectively, so these values met the requirements of SNI 0778: 2009 Sol Karet Cetak.

\section{Elongation at Break}

Elongation at break of the EVA/modified starch expanded compounds at different modified starch content was presented in Figure 2.

Figure 2 showed the elongation at break value of the EVA/modified starch expanded compounds was increasing along with the rising amount of tapioca starch up to $30 \mathrm{phr}$ and afterward, it decreasing with higher modified starch loading. Elongation at break of EVA compound without modified starch was $705.33 \%$. The addition of

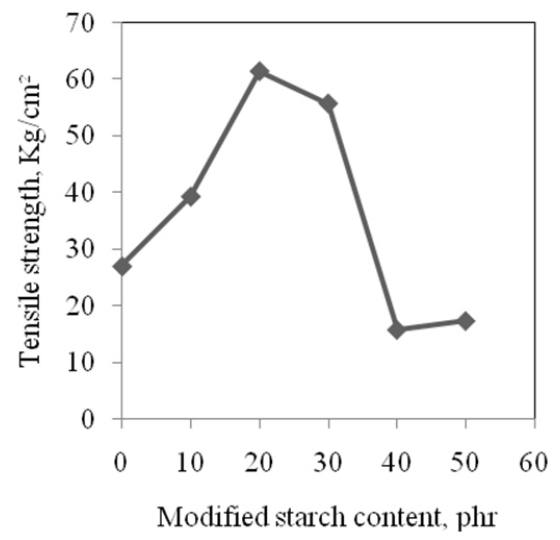

Figure 1. Tensile strength of the EVA/modified starch expanded compounds. modified starch of $10 \mathrm{phr}, 20 \mathrm{phr}$, and $30 \mathrm{phr}$ gave an enhancement in elongation at break of $16.64 \%$, $26.89 \%$, and $9.78 \%$ respectively, compared to the EVA compound without modified starch. The highest value of elongation at break value (895\%) was observed for samples containing $20 \mathrm{phr}$ modified starch.

According to Ali et al. (2013), an rise in the amount of starch increases the ductility of the sample. The addition of $40 \mathrm{phr}$ modified starch decreased elongation at break of $50.52 \%$ compared to the elongation at break of the EVA compound without modified starch. The decrease in elongation at break of EVA/starch composites suggested that the introduction of starch particles in the EVA matrix caused poor interactions between the EVA matrix and the starch particles (Hamadache et al., 2019).

Based on SNI 0778:2009 Sol Karet Cetak, the minimum elongation at break value was $150 \%$. From Figure 2, it can be seen that the elongation at break of all the expanded compounds met the requirements of SNI 0778:2009 Sol Karet Cetak.

\section{Tear Strength}

Tear strength used to measure the tear resistance is the force required to pull apart a material until it rips (Tang et al., 2019). The tear strength of the EVA/modified starch expanded compounds containing various modified starch were shown in Figure 3.

Figure 3 showed that an addition in the starch content (10 to $50 \mathrm{phr}$ ) led to an increasement in the tear strength of the blends. The tear strength also followed the same trends as tensile strength. The tear strength value of EVA compound without modified starch was $8.98 \mathrm{~N} / \mathrm{mm}$. The addition of $10 \mathrm{phr}$ of modified starch increased the tear

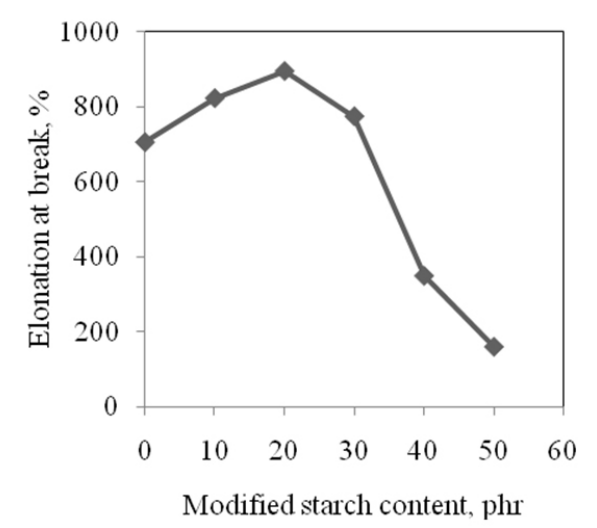

Figure 2. Elongation at break of the EVA/modified starch expanded compounds. 
strength value by $11.80 \%$. The optimum tearing strength $(16.62 \mathrm{~N} / \mathrm{mm})$ was observed for the EVA/ modified starch blends containing $20 \mathrm{phr}$ modified starch. The tear resistance can be affected by the number and size of micropores formed during the heat forming process. The large and uneven pore size resulted in low tear resistance.

According to ISO/TR 20880- Footwear Performance requirements for components for footwear - Outsoles, the minimum tear strength is $8,0 \mathrm{~N} / \mathrm{mm}$ (for density $\leq 0.9 \mathrm{~g} / \mathrm{cm}^{3}$ ) or $6.0 \mathrm{~N} /$ $\mathrm{mm}$ (for density $>0.9 \mathrm{~g} / \mathrm{cm}^{3}$ ). Therefore the tear strength of all the resulting expanded compounds met the requirements of ISO/TR 20880- Footwear - Performance requirements for components for footwear - Outsoles.

\section{Permanent Set}

The permanent set refers to the residual extension remaining after a material sample is stretched and released (Diani et al., 2009). The $50 \%$ permanent set was used in this research. The permanent set of the EVA/modified starch expanded compounds containing various modified starch were shown in Figure 4.

The lower the permanent set, the higher the ability of the material to retain its elasticity. EVA compound without modified starch showed a permanent set value of $8.21 \%$. The incorporation of 10; 20 and $50 \mathrm{phr}$ of modified starch to EVA compound had little influence on the permanent set of EVA compound. The optimum permanent set $(4.85 \%)$ was observed for the EVA/modified starch blends containing $30 \mathrm{phr}$ modified starch which meant a decrease of $40.93 \%$ compared to EVA compound without modified starch. The value of $50 \%$ permanent set required for the SNI rubber sole was $6 \%$ maximum. Therefore,

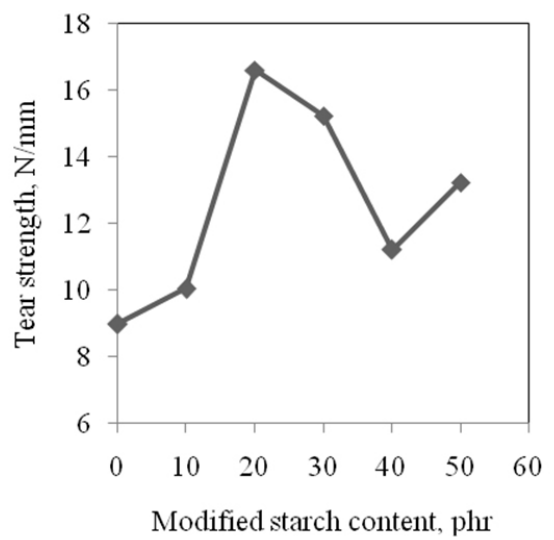

Figure 3. Tear strength of the EVA/modified starch blends. the EVA/modified starch expanded compound containing $30 \mathrm{phr}$ modified starch (MS30) met the Indonesia National Standard SNI 0778:2009 requirements.

\section{Density}

The density was defined by the difference of weight in air and water divided to weight of samples in air. As it could be seen, with the addition of 10-50 phr modified starch to EVA compounds, the sample densities increased (Figure 6). Similar results have been observed by Rodriguez-Perez et al. (2012) which an increase in the starch content leads to an increase in the density. The addition of $10 \mathrm{phr}$ modified starch to the EVA compound (MS0) increased the density by $3.67 \%$.

A higher density $\left(0.913 \mathrm{~g} / \mathrm{cm}^{3}\right)$ was observed for the EVA/modified starch expanded compound containing $20 \mathrm{phr}$ of modified starch. The density of this formulation may be influenced by the voids of a blend material and by the interface bond between the EVA matrix and starch. EVA matrix and modified starch that was not bonded properly caused low density due to the space around the starch which did not adhere to the matrix and vice versa. Interfacial characteristics between modified starch particles and EVA matrix as well as the microstructural difference gave a strong relationship between morphological. According to SNI 0778: 2009 Sol Karet Cetak, the maximum density value is $1.4 \mathrm{~g} / \mathrm{cm}^{3}$, and Figure 5 showed that the density of all expanded compounds met the requirements of the Indonesia National Standard SNI 0778: 2009 Sol Karet Cetak.

\section{Abrasion Resistance}

Abrasion resistance is the ability of a material to resist mechanical action such as rubbing, scraping

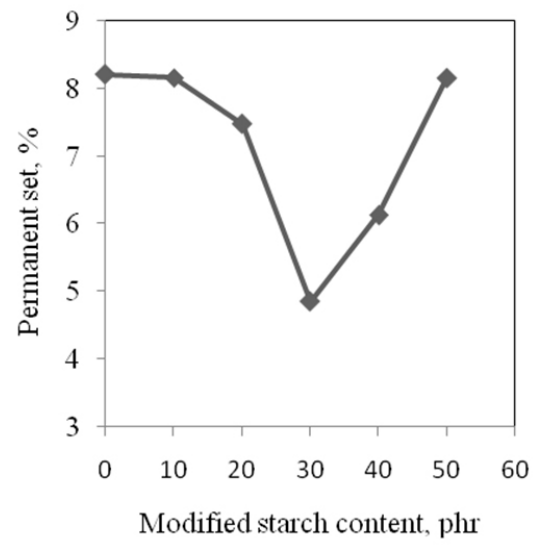

Figure 4. The permanent set of the EVA/modified starch expanded compounds. 
or erosion that tends progressively to remove material from its surface (Arayapranee, 2012). The smaller volume loss indicated better abrasion resistance. Abrasion resistance of the EVA/ modified starch expanded compounds containing various modified starch was shown in Figure 6. The enhancement of volume loss during the abrasion test compared to EVA compound without starch content was shown by an increasement in the amount of modified starch up to $20 \mathrm{phr}$. These indicated inhomogeneous mixing of the sample.

The addition of modified starch from 40 to 50 phr increased abrasion resistance. This abrasion enhancement with the presence of starch might be due to good interaction between modified starch and the EVA matrix of expanded compounds. Figure 6 showed that the smallest volume loss was 439.99 $\mathrm{mm}^{3}$ represented by the compound containing 30 phr of starch. The volume loss required by SNI 0778:2009 Sol Karet Cetak is a maximum of 350 $\mathrm{mm}^{3}$, this meant that all the compounds produced did not meet these requirements. Figure 8 showed the inhomogeneous dispersion and distribution of the starch particles in the EVA matrix.

\section{Flex Resistance}

Flex resistance is the ability to sustain numerous flexing cycles without the occurrence of crack or damage to the surface. The flexing resistance of the microcellular samples was determined using a Ross flexing machine. Flexing cycles required according to SNI 0778: 2009 Sol Karet Cetak is 150000 cycles. According to Mohamad Aini et al. (2019), the reduction of flexibility increases the stiffness of composites, resulting in the reduction of flexing resistance. Table 2 showed that the

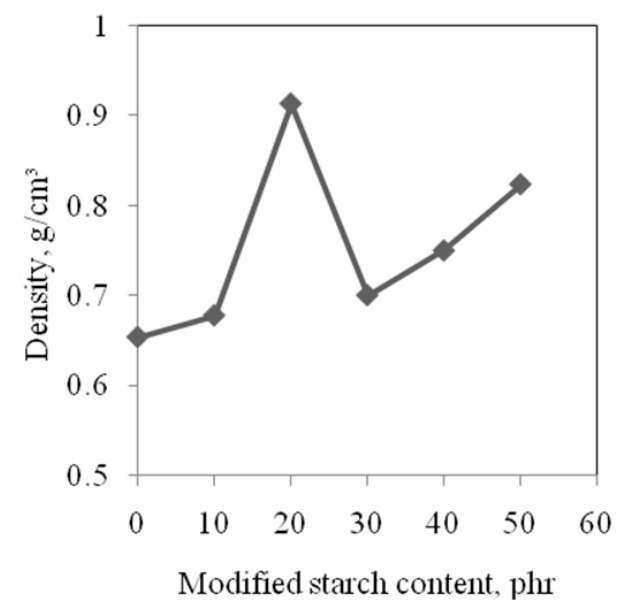

Figure 5. The density of the EVA/modified starch expanded compounds. addition of modified starch material up to $50 \mathrm{phr}$ still provided good flexing resistance.

Based on the flex resistance requirements of SNI 0778:2009 Sol Karet Cetak, all EVA/modified starch expanded compounds met the requirements of SNI 0778:2009 Sol Karet Cetak.

\section{Biodegradability}

The weight loss of EVA/modified starch expanded compound at different modified starch content after compost burial test were presented in Figure 6. It showed the weight loss of EVA/ modified starch generally increased with a rise in modified starch content and burial time. This weight loss might be due to the invasion of microorganisms into the blends sample. From the data in Figure 6, it was obvious that the EVA compound without modified starch (MS0) remained unchanged, even after 42 days, and no weight loss was noticed. This was due to the very small accessibility of starch to microorganism that affected in slow biodegradability rate. The EVA/ TPS blend with 10\% starch content showed fast weight loss up to 14 days, while for the next 28 days, the blend remained nearly unchanged. It indicated that the starch had been biodegraded in the first 14 days. The EVA/TPS blend with $50 \%$ modified starch content showed very fast in weight loss for the first 14 days.

The increasing content of starch in the EVA/ starch blend accelerated the rate of weight loss. It was due to the dispersed part of starch began to bond and became more interlinked. The higher weight loss $(13.61 \%)$ was measured for samples containing $50 \%$ modified starch in a period of 42 days. Thermoplastic starches have been reported

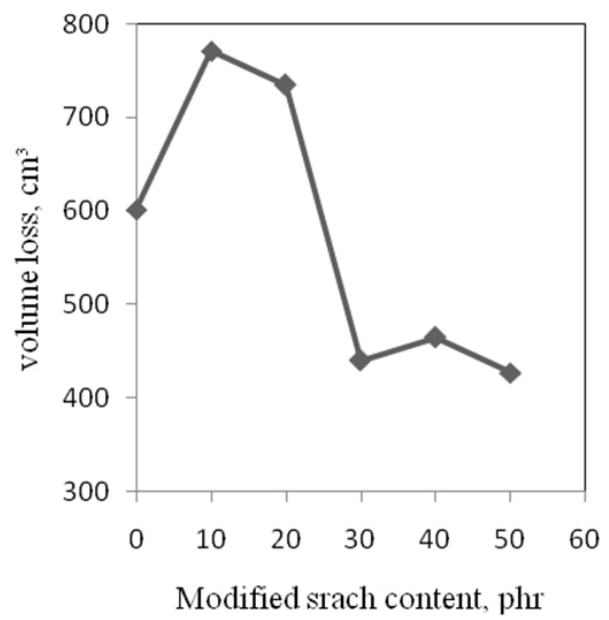

Figure 6. Abrasion resistance of the EVA/modified starch expanded compounds. 
Table 2. Flexing resistance of the EVA/modified starch expanded compounds.

\begin{tabular}{ccccccc}
\hline Testing & \multicolumn{5}{c}{ Formulation } \\
\cline { 2 - 7 } parameter & MS0 & MS10 & MS20 & MS30 & MS40 & MS50 \\
\hline Flexing resistance for 150kcs & crack & No crack & No crack & No crack & No crack & No crack \\
\hline
\end{tabular}

to provide better biodegradability (RodriguezPerez et al., 2012; Macedo \& Rosa 2015; Sessini et al., 2019).

Morphology of the EVA/modified Starch Expanded Compounds

Figure 8 showed the morphology image of the EVA/modified starch expanded compounds with different modified starch content; a (10 phr), b (20 phr), c (30 phr), d (40 phr), e (50 phr). It can be seen that the good dispersion of starch into the EVA matrix was observed by an expanded compound containing $20 \mathrm{phr}$ modified starch (Figure 8b). Figure 8 also showed that along with the increase of modified starch content the dispersion of modified starch became poor, and according to Guo et al. (2021) it caused agglomeration and resulted in the decrease of cell size uniformity. Figure 8e showed an image of the EVA/modified starch expanded compounds containing $40 \mathrm{phr}$ starch content, there were many large open cells due to starch agglomeration.

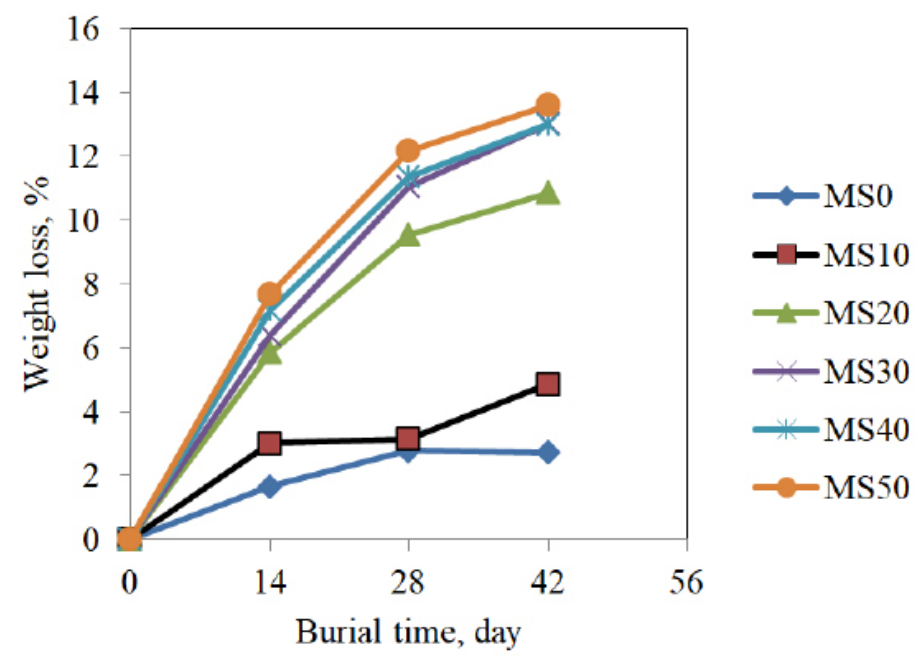

Figure 7. Weight loss of the EVA/modified starch as a function of burial time.

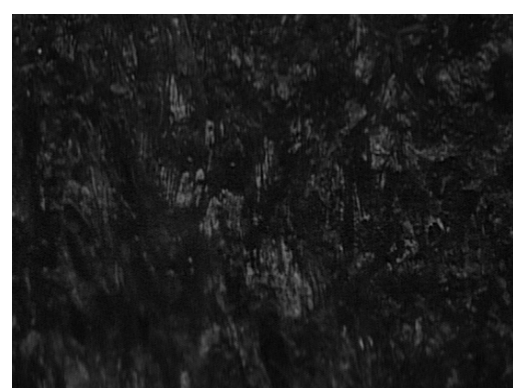

(a)

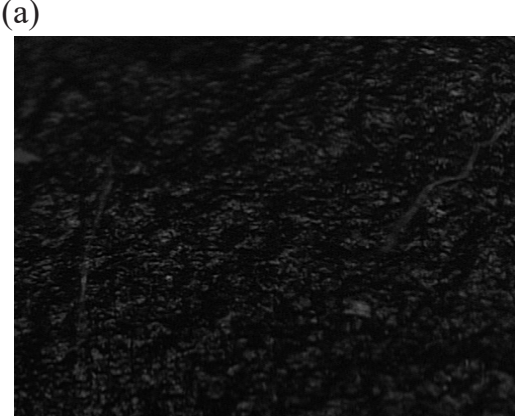

(d)

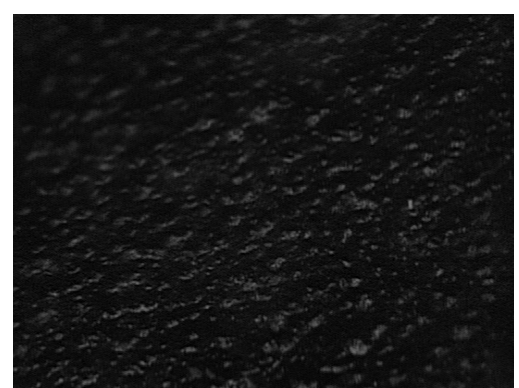

(b)

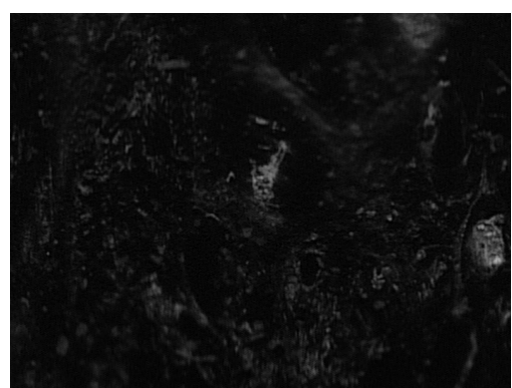

(c)

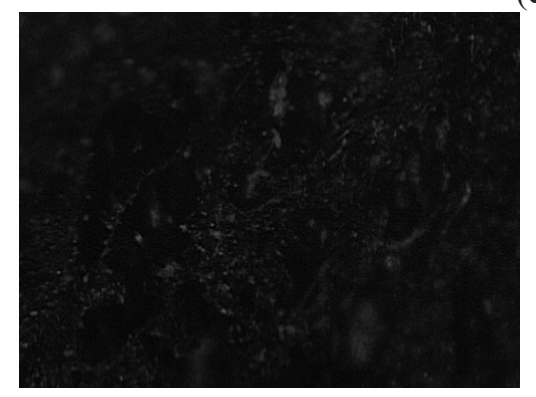

(e)

Figure 8. Morphology image of the EVA/modified starch expanded compounds with different modified starch content: a (10 phr), b (20 phr), c (30 phr), d (40 phr), e (50 phr). 


\section{CONCLUSIONS}

EVA/modified starch expanded compound with different modified starch contents $(0-50 \mathrm{phr})$ were prepared by mixing EVA, modified starch, and additives using a two-roll mill laboratory scale. The starch was tapioca starch that modified by mixing the starch with water and glycerol at 60:25:15 (starch:glycerol:water). Effect of modified starch content was characterized its tensile strength, elongation at break, tearing strength, $50 \%$ permanent set, density, abrasion resistance, flex resistance, biodegradability, and morphology. The optimum tensile strength (61.33 $\mathrm{kg} / \mathrm{cm}^{2}$ ) was obtained at $20 \mathrm{phr}$ modified starch loading. The highest value of elongation at break value $(895 \%)$ was observed for samples containing $20 \mathrm{phr}$ modified starch. The optimum tearing strength $(16.62 \mathrm{~N} / \mathrm{mm})$ was observed for the EVA/ modified starch blends containing $20 \mathrm{phr}$ modified starch. The addition of 10-50 phr modified starch to EVA compounds increased the density. A higher density $\left(0.913 \mathrm{~g} / \mathrm{cm}^{3}\right)$ was observed for the EVA/ modified starch expanded compound containing $20 \mathrm{phr}$ of modified starch. The EVA compound containing $30 \mathrm{phr}$ of starch showed the optimum $50 \%$ permanent set $(4.85 \%)$ and the highest abrasion resistance with the smallest volume loss of $439.99 \mathrm{~mm}^{3}$. The addition of modified starch up to $50 \mathrm{phr}$ still provided good flexural resistance to 150000 number of cycles. The biodegradation test was carried out by the burial method in the compost soil for up to 42 days, and the biodegradability was evaluated by weight loss percent. The higher weight loss $(13.61 \%)$ was measured for samples containing $50 \%$ modified starch in a period of 42 days. The increasement of modified starch content in the EVA matrix gave a poorer dispersion of modified starch. In general, the results of the EVA/ modified starch expanded compound test have met the requirements of SNI 0778: 2009 Sol Karet Cetak, but the abrasion resistance was still below the quality requirements.

\section{ACKNOWLEDGEMENTS}

This research was funded by the Indonesian government under DIPA 2020. The authors are grateful to the Head of Center for Leather, Rubber and Plastics, and to Research Team for the support during the research that has been conducted.

\section{REFERENCES}

Abdullah, Z., \& Ibrahim, K. M. Y. K.(2014). Electrical tracking performance of thermoplastic elastomer nanocomposites material under high voltage application. International Journal of Scientific \& Engineering Research, 5(12), 708-711.

Ali, R. R., Rahman, W. A. W. A., Kasmani, R. M., Ibrahim, N., Mustapha, S. N. H., \& Hasbullah, H. (2013). Tapioca starch biocomposite for disposable packaging ware. Chemical Engineering Transactions, 32, 1711-1716. https:// doi.org/10.3303/CET1332286

Arayapranee, W. (2012). Rubber abrasion resistance. In. M. Adamiak (Ed.), Abrasion resistance of materials (pp. 147-166). https://doi. org $/ 10.5772 / 30556$

Ayu, R. S., Khalina, A., Harmaen, A. S., Zaman, K., Jawaid, M., \& Lee, C. H. (2018). Effect of modified tapioca starch on mechanical, thermal, and morphological properties of PBS blends for food packaging. Polymers, 10(11), 1187. https:// doi.org/10.3390/polym 10111187

BSN (Badan Standardisasi Nasional). (2009). SNI 0778:2009 Sol karet cetak. Jakarta, Indonesia: BSN.

Dias, R. B., Coto, N. P., Batalha, G. F, \& Driemeier, L. (2018). Systematic study of ethylene-vinyl acetate (EVA) in the manufacturing of protector devices for the orofacial system. In L. A. Dobrzański (Ed.), Biomaterials in regenerative medicine. https://doi.org/10.5772/intechopen.69969

Da Róz, A. L., Ferreira, A. M., Yamaji, F. M., \& Carvalho. A. J. F. (2012). Compatible blends of thermoplastic starch and hydrolyzed ethylenevinyl acetate copolymers. Carbohydrate Polymer, 90(1), 34-40. https://doi.org/10.1016/j. carbpol.2012.04.055

Diani, J., Fayolle, B., \& Gilormini, P. (2009). A review on the Mullins effect. European Polymer Journal, 45(3), 601-612. https://doi.org/10.1016/j. eurpolymj.2008.11.017

Ferreira, E. J., Dias, M. M., \& Schneider, E. L. (2018). Analysis of non-uniform expansion behavior of injected EVA. Academic Journal of Polymer Science, 1(4), 61-65. https://doi.org/10.19080/ AJOP.2018.01.555569

Gautam, N., \& Kaur, I. (2013). Soil burial biodegradation studies of starch grafted polyethylene and identification of Rhizobium meliloti therefrom. Journal of Environmental Chemistry and Ecotoxicology, 5(6), 147-158.

Guo, Y., Hao, X., \& Liang, G. (2021). Modification and properties of EVA foamed material with hemp stem powder. Journal of Physics: Conference Series, 1759, 012013. $\quad$ https://doi.org/10.1088/1742$\underline{6596 / 1759 / 1 / 012013}$

Hamadache, H., Djidjelli, H., Boukerrou, A., Kaci, M., Jofre-Reche, J. A., \& Martín-Martínez, J. M. (2019). Different compatibility approaches to 
improve the thermal and mechanical properties of EVA/starch composites. Polymer composites, 40, 3242-3253. https://doi.org/10.1002/pc.25179

ISO (International Standard Organization). (2015). ISO 34-1:2015(E) Rubber, vulcanized or thermoplastic - Determination of tear strength - Part 1: Trouser, angle, and crescent test pieces. Geneva, Switzerland: International Standard Organization.

ISO (International Standard Organization). (2017). ISO 37:2017(E) Rubber vulcanized or thermoplasticDetermination of tensile stress-strain properties. Geneva, Switzerland: International Standard Organization.

ISO (International Standard Organization). (2018). ISO 2781:2018(E) Rubber, vulcanized or thermoplastic - Determination of density (Method A). Geneva, Switzerland: International Standard Organization.

Lopes, D., Ferreira, M. J., Russo, R., \& Dias, J. M. (2015). Natural and synthetic rubber/wasteethylene-vinyl acetate composites for sustainable application in the footwear industry. Journal of Cleaner Production, 92, 230-236. https://doi. org/10.1016/j.jclepro.2014.12.063

Maran, J. P., Sivakumar, V., Thirugnanasambandham, K., \& Sridhar, R. (2014). Degradation behavior of bioreactive blends based on cassava starch buried under indoor compost conditions. Carbohydrate Polymer, 101, 20-28. https://doi.org/10.1016/j. carbpol.2013.08.080

Mendes, J. F., Paschoalin, R. T., Carmona, V. B., Neto, A. R. S., Marques, A. C. P., Marconcini, J. M., Mattoso, L. H. C., Medeiros, E. S., \& Oliveira, J. E. (2016). Biodegradable polymer blends based on corn starch and thermoplastic chitosan processed by extrusion. Carbohydrate Polymers, 137, 452-458. $\quad$ https://doi.org/10.1016/j. carbpol.2015.10.093

Mohamad Aini, N. A., Othman, N., Hussin, M., Sahakaro, K., \& Hayeemasae, N. (2019). Hydroxymethylation-modified lignin and its effectiveness as a filler in rubber composites. Processes, 7(5), 315. https://doi.org/10.3390/ pr7050315

Macedo, J. R. N., \& Rosa, D. S. (2015). Effect of fiber and starch incorporation in biodegradation of PLA-TPS-Cotton composites. Key Engineering Materials, 668, 54-62. https://doi.org/10.4028/ www.scientific.net/KEM.668.54

Nautiyal, O. H. (2012). Molding of EVA soles using expanding and reducing agents. International Journal of Engineering Science and Technology, 4(7), 3050-3058.

Obasi, H. C., \& Igwe, I. O. (2014). Cassava starchmixed polypropylene biodegradable polymer: Preparation, characterization, and effects of biodegradation products on growth of plants International Journal of Science and Research,
3(7), 802-807.

Onodera, A. N., Neto, W. P. G., Roveri, M. I., Oliveira, W. R., \& Sacco, I. C. N. (2017). Immediate effects of EVA midsole resilience and upper shoe structure on running biomechanics: A machine learning approach. PeerJ., 5, e3026. https://doi. org/10.7717/peerj.3026

Rodriguez-Perez, M. A., Simoes, R. D., RomanLorza, S., Alvarez-Lainez, M., Montoya-Mesa, C., Constantino, C. J. L., \& de Saja, J. A. (2012). Foaming of EVA/starch blends: Characterization of the structure, physical properties, and biodegradability. Polymer Engineering and Science, 52(1), 62-70. https://doi.org/10.1002/ pen.22046

Sessini, V., Arrieta, M. P., Raquez, J. M., Dubois, P., Kenny, J. M., \& Peponi, L. (2019). Thermal and composting degradation of EVA/Thermoplastic starch blends and their nanocomposites. Polymer Degradation and Stability, 159, 184-198. https:// doi.org/10.1016/j.polymdegradstab.2018.11.025

Sisanth, K. S., Thomas, M. G., Abraham, J., \& Thomas, S. (2017). General introduction to rubber compounding. In S. Thomas, \& H. J. Maria (Eds.), Progress in rubber nanocomposites (pp. 1-39). https://doi.org/10.1016/B978-0-08100409-8.00001-2

Tanase, E. E., Popa, M. E., Rapa, M., Popa, O., \& Popa, I. V. (2016). Biodegradation study of some food packaging biopolymers based on PVA. Bulletin of University of Agricultural Sciences and Veterinary Medicine Chi-Napoca. Animal Science and Biotechnologies, 73(1), 89-94. https://doi.org/10.15835/buasvmcn-asb:11948

Tang, L. C., Zhao, L., Qiang, F., Wu, Q., Gong, L. X., \& Peng, J. P. (2019). Mechanical properties of rubber nanocomposites containing carbon nanofillers. In S. Yaragalla, R. K. Mishra, S. Thomas, N. Kalarikkal, \& H. J. Maria (Eds.), Carbon-based nanofillers and their rubber nanocomposites: Fundamentals and applications (pp. 367-423). https://doi.org/10.1016/B978-0-12-817342$\underline{8.00012-3}$

Valle, V., Encalada, K., Aldás, M. B., \& Proaño, E. (2018). An overview of starch-based biopolymers and their biodegradability. Ciencia e Ingeniería, 39(3), 245-258.

Wang, L., Hong, Y., \& Li, J. X. (2012). Durability of running shoes with ethylene vinyl acetate or polyurethane midsoles. Journal of Sports Sciences, 30(16), 1787-1792. https://doi.org/ 10.1080/02640414.2012.723819

Zimmermann, M. V. G., Turellaa, T., Santana, R. M. C., \& Zattera, A. J. (2014). Comparative study between poly(ethylene-co-vinyl acetate)-EVA expanded composites filled with banana fiber and wood flour. Materials Research, 17, 1535-1544. 
